\title{
CONSUMPTION IN SOUTH AMERICA: MYOPIA OR LIQUIDITY CONSTRAINTS?
}

\author{
Fábio Augusto Reis Gomes * \\ Lourenço Senne Paz ${ }^{\dagger}$
}

\begin{abstract}
In this paper, we consider Brazil, Colombia, Peru, and Venezuela for a study on aggregate consumption behavior, in which we test the life cyclepermanent income hypothesis prediction that consumption growth depends only on the interest rate. Nevertheless, our results suggest that in general predicted income is a relevant covariate. We checked for some possible reasons behind this result, namely liquidity constraints, myopia and perverse asymmetry. We found support for liquidity constrained consumers in Brazil and Colombia, and perverse asymmetry for Peru. Finally, the results were uninformative about consumption in Venezuela.
\end{abstract}

Keywords: South America, consumption, permanent income, liquidity constraints, myopia.

JEL classification: C22, E21

\section{Introduction}

The behavior of consumption has been studied for several decades, and one important theoretical approach used to describe it is the life cycle-permanent income hypothesis (LCH-PIH). This framework consists of an intertemporal consumer problem, in which predictable changes in income should not affect consumption and that consumption growth should respond only to interest rate, since its fluctuations affect how consumers smooth their consumption.

Hall (1978) solved a particular case of the consumer problem making use of the rational expectation hypothesis ( $\mathrm{REH})$, quadratic utility function, and constant interest rates. This set-up implies that consumption is a random walk, yet Hall's empirical evidence did not support his theoretical model predictions. Later, Flavin (1981) reached the same type of stochastic process for consumption, by keeping the constant interest rate assumption but without relying upon a specific utility function. Her empirical results also rejected the $\mathrm{PIH}$, and her diagnostic was that consumption is excessively sensitive to income, which could be a result of liquidity constraints, as discussed in Flavin (1985) and reinforced by Zeldes (1989) and Jappelli \& Pagano (1989).

When the constant interest rate assumption is relaxed, researchers commonly assume a joint log-normal distribution of consumption and interest

\footnotetext{
* Insper Institute e-mail: FabioARG@isp.edu.br

† Dept. of Economics, Syracuse University e-mail: 1spaz@maxwell.syr.edu
} 
rate, which delivers a log-linearized version of the Euler Equation, which can be easily estimated. Nevertheless, this specification has not been successful in empirical works (Mankiw 1981, Hansen \& Singleton 1983, Hall 1978, Yogo 2004).

Campbell \& Mankiw (1989) extended the LCH-PIH framework to incorporate a rule-of-thumb behavior, where a fraction of consumers consumes only their current income. Using G7 country data, Campbell \& Mankiw (1989, 1990) concluded that this rule-of-thumb behavior was widespread, in particular, for the U.S. economy they estimated that about $50 \%$ of total income belonged to rule-of-thumb consumers. Therefore, Campbell and Mankiw's results cast doubts on the consumer's optimization behavior. However, the main candidate to explain this result remains the lack of credit (Vaidyanathan 1993, Engelhardt 1996, Garcia et al. 1997, Sarno \& Taylor 1998, Brady 2008) ${ }^{1}$.

As discussed by Shea $(1995 a, b)$, predictable income changes could affect consumption if consumers display myopic behavior (also known as Keynesian or rule-of-thumb consumers) or are credit constrained. Thus, while myopia causes a symmetric relationship between consumption growth and predicted income growth, liquidity or credit constraints imply that LCH-PIH should fail only because consumers cannot borrow when income decreases, then consumption should be more strongly related to predictable income increases than decreases ${ }^{2}$. Shea (1995a) analyzed the U.S. case using aggregate time series, finding that consumption is more sensitive to consumption decreases than increases, which is an unexpected result. Also for the U.S., Shea (1995a) found the same results using the PSID and Garcia et al. (1997) found that unconstrained consumers exhibit this behavior too.

The purpose of our paper is to test the ability of the LCH-PIH to explain consumption behavior in four South American countries: Brazil, Colombia, Peru and Venezuela. Moreover, we will follow Shea (1995a) and go beyond the Campbell and Mankiw approach in order to consider the possibility of myopia and credit constraint. To the best of our knowledge, this is the first paper to investigate these questions using data for these South American countries from the Penn World Table (Heston et al. 2006).

Few studies focused on consumption in South American countries in part due to lack of data. Indeed, it seems that only Gomes \& Paz (2004) analyzed this region. They used CM's approach and Penn World Table 6.1 (Heston et al. 2002) annual data from 1951 to 2000. Their results indicate that LCH-PIH does not hold for Brazil, Peru and Colombia and a significant share of income of these countries belong to consumers of the Keynesian type.

If we consider countries individually, the amount of literature increases considerably. For example, there is a lot of research for Brazil using the CM framework and their findings strongly support that consumption growth depends on predicted income growth (Cavalcanti 1993, Reis et al. 1998, Issler \& Rocha 2000, Gomes 2004, Gomes et al. 2005). Nevertheless, there are only two papers discussing the reasons behind the failure of the LCH-PIH.

The first is Paz (2006), who was the first to employ the Shea (1995a) procedure using Brazilian quarterly data from 1991:1 to 2004:4. For consumption

\footnotetext{
${ }^{1}$ Other possibilities are, for instance, precautionary savings (Carrol 1997, Madsen \& McAleer 2000, Gourinchas \& Parker 2001) and self-control problems that emerge in models with hyperbolic discounting (Angeletos et al. 2001).

${ }^{2}$ This asymmetric pattern was previously discussed by Altonji \& Siow (1987).
} 
data he used the real household final consumption per capita from Ipeadata, and his real interest data was constructed from the Selic nominal interest rate, and used the IGP-DI as the inflation index. His findings indicate that neither liquidity constraints nor myopic consumers could generate the fact that consumption is sensitive only to expected income declines, i.e. Brazilian households exhibited the Shea's (1995b) "perverse asymmetry".

The second paper is Gomes (2010) that used Brazilian annual data from 1947 to 2005. His consumption and income data were, respectively, household final consumption and gross disposable income; the per capita series were obtained using the mid-period population. These data were extracted from Ipeadata. Real interest data were constructed from the CDB (bank certificates of deposit) and savings account, using the IGP-DI inflation index to obtain real interest series. The results found by Gomes (2010) could not reject the presence of myopia and liquidity constraints in Brazil.

As we can see from these two studies, the data used and the results obtained can be very different and it becomes difficult to draw conclusions across studies, let alone across countries, because it is not clear to what extent the results differ due to different data. Furthermore, given the similarities among these four South American countries found in Gomes \& Paz (2004), it would be interesting to find out if the reasons behind the rejection of LCH-PIH are the same in these countries, and to accomplish that it is essential to use a data set with assembled with similar methodologies for all countries.

Finally, based on CM's and Shea (1995a) methodology, the empirical findings of our paper indicate that LCH-PIH is not valid for any country under analysis. For Brazil, contrary to Paz (2006) findings and in line with Gomes (2010), there was support for liquidity constraints. Colombia also showed signs of liquidity constraints. Shea's perverse asymmetry seems to be the case for Peru. Last but not least, the results for Venezuela were uninformative about the causes behind the rejection of the LCH-PIH.

The paper is organized as follows. In section 2 the theoretical model for aggregate consumption is presented. Then in section 3 the econometric methodology and the data set used are described. Section 4 reports and discusses the regressions' outputs. The results are discussed in section 5. The last section summarizes the conclusions.

\section{Theoretical model for aggregate consumption}

Following Hall (1978), the rational and forward-looking consumer maximizes her utility by solving the following problem:

$$
\begin{gathered}
\underset{\left\{c_{t+i}\right\}_{i=0}^{\infty}}{\operatorname{Max}} E_{t}\left\{\sum_{i=0}^{\infty}\left[\beta^{i} u\left(C_{t+i}\right)\right]\right\} \\
\text { s.t. } A_{t+1+i}=\left(A_{t+i}+Y_{t+i}-C_{t+i}\right)\left(1+r_{t+1+i}\right)
\end{gathered}
$$

where $A_{t}, Y_{t}, C_{t}$ e $r_{t}$ are, respectively, wealth, income, consumption and real interest rate in period $t$, while $\beta$ is the discount factor. Thus, subject to the budget constraint, the consumers optimize their entire stream of consumption. The solution $\left\{C_{t}^{*}\right\}_{t=0}^{\infty}$ is described by an equation called Euler Equa- 
tion that is depicted in equation (1) below.

$$
u^{\prime}\left(C_{t}\right)=\beta E_{t}\left[u^{\prime}\left(C_{t+1}\right)\left(1+r_{t+1}\right)\right] .
$$

When the utility function is of the CRRA type, equation (1) becomes:

$$
\beta E_{t}\left[\left(\frac{C_{t+1}}{C_{t}}\right)^{-\sigma}\left(1+r_{t+1}\right)\right]=1,
$$

where $\sigma$ is the coefficient of relative risk aversion. Thus, with homoskedasticity and joint conditional log-normality of asset returns and consumption, the Euler Equation becomes ${ }^{3}$

$$
\Delta c_{t}=\alpha_{1}+\frac{1}{\sigma} \hat{r}_{t}+\varepsilon_{t}
$$

where $c_{t}=\ln \left(C_{t}\right), \Delta c_{t}$ is consumption growth between $t-1$ and $t, \hat{r}_{t}$ is the expected real interest rate between $t-1$ and $t, \varepsilon_{t}$ is the error term and $\alpha_{1}$ is a function of $\beta$, and the variance of $\varepsilon_{t}, \sigma$. Thus, the LCH-PIH points out that consumption growth should respond only to the expected real interest rate and $\Delta c_{t}$ should not be affected by expected changes in her future income.

Mankiw (1981), Hansen \& Singleton (1983), Hall (1978) and Yogo (2004) estimated equation (3) obtaining poor results. Basically, the elasticity of intertemporal substitution,

$1 / \sigma$, is close to zero. According to $\mathrm{CM}$, a better model to explain the consumption time series behavior is given by having two types of consumers. The first consume according to the LCH-PIH, i.e. equation (3), and the second follows a simple rule of thumb: consume her current income. In order to evaluate this conjecture, CM proposed the following specification given by equation (4):

$$
\Delta c_{t}=\lambda \Delta \hat{y}_{t}+(1-\lambda)\left[\alpha_{1}+\frac{1}{\sigma} \hat{r}_{t}+\varepsilon_{t}\right]
$$

in which $y_{t}=\ln \left(Y_{t}\right), \Delta \hat{y}_{t}$ is expected income growth between $t-1$ and $t$. Then, the following reduced form was estimated by them:

$$
\Delta c_{t}=\alpha_{2}+\lambda \Delta \hat{y}_{t}+\phi \hat{r}_{t}+\xi_{t}
$$

where $\alpha_{2}=(1-\lambda) \alpha_{1}, \phi=(1-\lambda) / \sigma$ and $\xi_{t}=(1-\lambda) \varepsilon_{t}$. Following CM, $\Delta \hat{y}_{t}$ and $\hat{r}_{t}$ were set as linear projections of ex-post income change and ex-post real interest rate on variables in the $t-1$ information set.

By controlling for the returns to savings, the LCH-PIH implies that predictable income changes should not affect consumption, which is the case if the estimated $\lambda$ is zero. If estimated $\lambda$ is different from zero, we will consider the two alternative hypotheses: myopic consumers and liquidity constraints. In the former consumption tracks the current income (i.e. they consume a fixed share of current income) and, as a consequence, consumption should increase and decrease in response to increases and decreases in the expected income, respectively. In the latter, however, agents are allowed to save but not to borrow, thus consumption should be more correlated with expected income

\footnotetext{
${ }^{3}$ This approach was used by many authors, e.g. Hansen \& Singleton (1983), Hall (1978), Yogo (2004).
} 
increases, since in bad times agents cannot borrow in order to increase consumption. Building on these conjectures Shea (1995a) proposed the following model specification, equation (6), which could be used to infer the existence of liquidity constraints and myopia.

$$
\Delta c_{t}=\alpha+\gamma\left(\operatorname{Pos}_{t}\right)\left(\Delta \hat{y}_{t}\right)+\theta\left(N e g_{t}\right)\left(\Delta \hat{y}_{t}\right)+\phi \hat{r}_{t}+\varepsilon_{t},
$$

where $\mathrm{Pos}_{t}$ is a dummy variable equal to 1 for periods in which $\Delta \hat{y}_{t}>0$ and zero otherwise, and $N e g_{t}=1-P_{0 s}$, i.e. is equal to 1 when $\Delta \hat{y}_{t}<0$. The LCH-PIH implies that $\gamma=\theta=0$. Under myopia, $\gamma$ and $\theta$ should be equal and significantly larger than zero. But liquidity constraints imply that $\gamma$ is positive, statistically significant, and greater than $\theta$. Indeed, when the opposite occurs $(\gamma<\theta)$, consumption is much more sensitive to declines in expected income than increases, being what Shea (1995a) called "perverse asymmetry". A possible explanation for the perverse asymmetry is that agents have loss aversion type of preferences which have the property of attaching more importance to decrease than to increase in utility by the same amount. See Kahneman \& Tversky (1984) for more on loss aversion preferences.

The implementation of these models relies on a practical issue: the availability of non-durable consumption series. Indeed, as discussed in the next section, we do not have this information for the countries under analysis. Thus, we follow the Sarantis \& Stewart (2003) approach to estimate an aggregate consumption model taking into account that consumption series are the sum of durables and non-durables products.

Sarantis \& Stewart (2003) crucial assumption is that the proportion of durable, $C D_{t}$, to non-durable, $C_{t}$, expenditures is relatively constant through time, hence equation (7) becomes a reasonable approximation a reasonable approximation of total consumption.

$$
T C_{t}=C_{t}^{\eta_{1}} C D_{t}^{\eta_{2}}
$$

To model the non-durables expenditure we use the Hall (1978) approach and for the non-durables the Mankiw (1982) and Caballero (1994) approach ${ }^{4}$. Mankiw (1982) applied Hall's (1978) principal insight to the services from durables, yielding a model where durable expenditure follows an MA(1) process. The consumer problem is now described by the following equations

$$
\begin{gathered}
\underset{\left\{c_{t+i}\right\}_{i=0}^{\infty}}{\operatorname{Max}} E_{t}\left\{\sum_{i=0}^{\infty}\left[\beta^{i} u\left(k_{t+i}\right)\right]\right\}, \\
\text { s. t. }\left\{A_{t+1+i}=\left(A_{t+i}+Y_{t+i}-C D_{t+i}\right)\left(1+r_{t+1+i}\right) k_{t+1+i}=(1-\delta) k_{t+i}+C D_{t+i}\right.
\end{gathered}
$$

where $k_{t}$ is the stock of goods providing services to the consumer, $\delta$ is the depreciation rate of the consumer's stock and the second restriction is the law of motion of the stock of durable goods. Furthermore, Sarantis \& Stewart (2003) had to assume that rule-of-thumb (myopic) consumers spend all their income on non-durables; although, "We would be surprised if they did not spend a small proportion on durables, such as televisions, etc." (Sarantis \& Stewart 2003, p.1155). As discussed in Sarantis \& Stewart (2003), Caballero

\footnotetext{
${ }^{4}$ To save space, we present only the Mankiw's (1982) model.
} 
(1994) assumed that consumers' reaction to shocks is slow, which delivers the following form for the flow of durables

$$
\Delta \ln C D_{t}=\mu^{D}+\frac{1}{\sigma} r_{t}+v_{t}+\xi_{1} v_{t-1}+\xi_{2} v_{t-2}
$$

where $v_{t}$ is a innovation. Taking logs and the first difference of equation (7), and then substituting equations (3) and (8) into the resulting expression, we obtain:

$$
\Delta \ln T C_{t}=\mu+\frac{1}{\tilde{\sigma}} r_{t}+\tilde{v}_{t-1}+\xi_{1} \tilde{v}_{t-1}+\xi_{2} \tilde{v}_{t-2}
$$

This equation can be used to test the CM and the Shea models using total consumption data. This approach was first used by Sarantis \& Stewart (2003) with CM's model and we extend it us to estimate Shea's model. Thus, our empirical analysis is based on the following equations:

$$
\begin{gathered}
\Delta \ln T C_{t}=\mu+\lambda \Delta \ln Y_{t}+\phi r_{t}+\tilde{v}_{t-1}+\xi_{1} \tilde{v}_{t-1}+\xi_{2} \tilde{v}_{t-2} \\
\Delta \ln T C_{t}=\mu+\gamma\left(P o s_{t}\right) \Delta \ln Y_{t}+\theta\left(N e g_{t}\right) \Delta \ln Y_{t}+\phi r_{t}+\tilde{v}_{t-1}+\xi_{1} \tilde{v}_{t-1}+\xi_{2} \tilde{v}_{t-2}
\end{gathered}
$$

\section{Econometric Methodology and Data}

The methodology used in this paper consists of estimating equation (10) for each country in our sample. If a positive and statistically significant $\lambda$ coefficient is found, we then proceed with the estimation of equation (11) to infer the possible causes of LCH-PIH rejection. Both equations (10) and (11) should be estimated by two-stage least squares (2SLS). The previous literature has used lags of variables that appear in the test equation as instruments.

The novelty in the econometric specification is the MA(2) error process which requires special care when choosing the instruments, in other words, the use of the first two lags should be discouraged. On the other hand, the larger the lag the smaller the correlation of the endogenous right hand side variable with the instrument. So, we follow Sarantis \& Stewart (2003) by using instruments with a minimum lag of 2 and 3 periods. Furthermore, we conduct Hansen-Sargan over-identification tests to analyze for the specification validity and if the MA(2) error term is relevant for our annual data. Additionally, we calculate the Shea's Partial $R^{2}$. The Shea's Partial $R^{2}$ is presented in Shea (1997) and it is a measure of instruments predictive power. In general, the larger the Shea's Partial $R^{2}$ the better is the set of instruments. The use of this measure is important because instruments with low predictive power can generate imprecise or even spurious estimates as explained in Nelson \& Startz (1990).

Our dataset contains the natural logarithm of per capita real income $\left(y_{t}\right)$ and the natural logarithm of per capita real consumption $\left(c_{t}\right)$ from the Penn World Table version 6.2 (Heston et al. 2006). The consumer price index (used to calculate the inflation, $(\pi t)$ and nominal interest data come from the IFS (2008), which like the Penn World Tables provides comparable cross-country data. The nominal interest rate $\left(i_{t}\right)$ data scarcity limited the countries encompassed by our sample to Brazil, Colombia, Peru and Venezuela. Another difficulty was the lack of consumer price data for Brazil in the IFS database. Thus, we used the wholesale price index from the IFS and the IGP-DI. The nominal interest series used were the money market rate for Brazil and the 
discount rate for Colombia, Peru and Venezuela. The real interest rate $\left(r_{t}\right)$ is calculated according to the formula: $1+r_{t}=\left(1+i_{t}\right) /\left(1+\pi_{t}\right)$.

Our sample period is $1950-2003^{5}$ making a total of 54 observations, but the regressions had only 48 observations due to the use of lagged instruments. We conducted estimations using several lists of instruments, in particular we faced the complications posed by the MA(2) error term by using instrument sets with initial lags of 2 and 3. A natural way of checking the relevance of the using instruments from the third lag would be the Hansen-Sargan overidentification test. If the error term were really a MA(2), the instrument sets containing second lags would be rejected by this test. We can certainly make the point that the over-identification test may not have enough power; however, the results obtained from using instrument sets starting from the second and from the third lags were very similar. After all, we chose seven sets of instruments as representative of all the estimations we conducted. The instrument lists used are depicted below:

List 1: $i_{t-3}, \ldots, i_{t-6}, \Delta c_{t-3}, \ldots, \Delta c_{t-6}, \Delta y_{t-3}, \ldots, \Delta y_{t-6}, r_{t-3}, \ldots, r_{t-6}$

List 2: $i_{t-2}, \ldots, i_{t-6}, \Delta c_{t-2}, \ldots, \Delta c_{t-6}, \Delta y_{t-2}, \ldots, \Delta y_{t-6}, r_{t-2}, \ldots, r_{t-6}$

List 3: $\Delta y_{t-2}, \ldots, \Delta y_{t-6}, r_{t-2}, \ldots, r_{t-6}$

List 4: $\Delta c_{t-2}, \ldots, \Delta c_{t-6}, r_{t-2}, \ldots, r_{t-6}$

List 5: $\Delta c_{t-2}, \ldots, \Delta c_{t-6}, r_{t-2}, \ldots, r_{t-6} \Delta y_{t-2}, \ldots, \Delta y_{t-6}, c y_{t-2}$

List 6: $i_{t-2}, \ldots, i_{t-6}, r_{t-2}, \ldots, r_{t-6}$

List 7: $i_{t-2}, \ldots, i_{t-6}, r_{t-2}, \ldots, r_{t-6}, \Delta c_{t-2}, \ldots, \Delta c_{t-6}, \Delta y_{t-2}, \ldots, \Delta y_{t-6}, c y_{t-2}$

where $\Delta y_{t-2}, r_{t-2}$, and $i_{t-2}$ are defined as before, and $c y_{t-2}$ is the consumption share of the income in $t-2$

\section{Results}

In tables 1 and 2 we present the estimates of equations (10) and (11) for Brazilian data, with the inflation calculated using the wholesale price index and the IGP-DI respectively. Column (1) on table 1 shows that the point estimate of $\lambda$ from equation (10) ranges from 0.297 to 0.906 , but only the regressions using the instrument sets $1,2,5$, and 7 are statistically significant at the $5 \%$ level, and if we consider only these regressions, we have $\lambda \in[0.828,0.906]$. These regressions are also the ones with the highest Shea's Partial $R^{2}$ (column 2) for the $\Delta y$ first-stage regression ${ }^{6}$, which means that these instrument sets are more correlated with the observed growth in income. Column (3) shows that there was no rejection at the $5 \%$ level in the Hansen-Sargan over-identification test

Table 2 contains estimates for Brazil when the inflation rate and the real interest rate are calculated with the IGP-DI price index. The results are qualitatively similar to the previous table, but now the statistically significant $\lambda$ ranges from 0.734 to 1.063 . Again, the instrument sets with the lowest Shea's Partial $R^{2}$ are the ones that do not produce statistically significant $\lambda$ estimates. From column (3) we can see that there are no rejections in the overidentification tests. Last but not least, our estimates are larger than the ones from the previous literature but not too far, since Reis et al. (1998) estimated $\lambda$ is 0.8 , Issler \& Rocha (2000) estimate was 0.74, Gomes \& Paz (2004) found

\footnotetext{
${ }^{5}$ The Penn World Table does not contain 2004 data for Brazil, Colombia, and Peru.

${ }^{6}$ The Shea's Partial $R^{2}$ results for the first-stage regression for the interest rate are not reported to save space.
} 


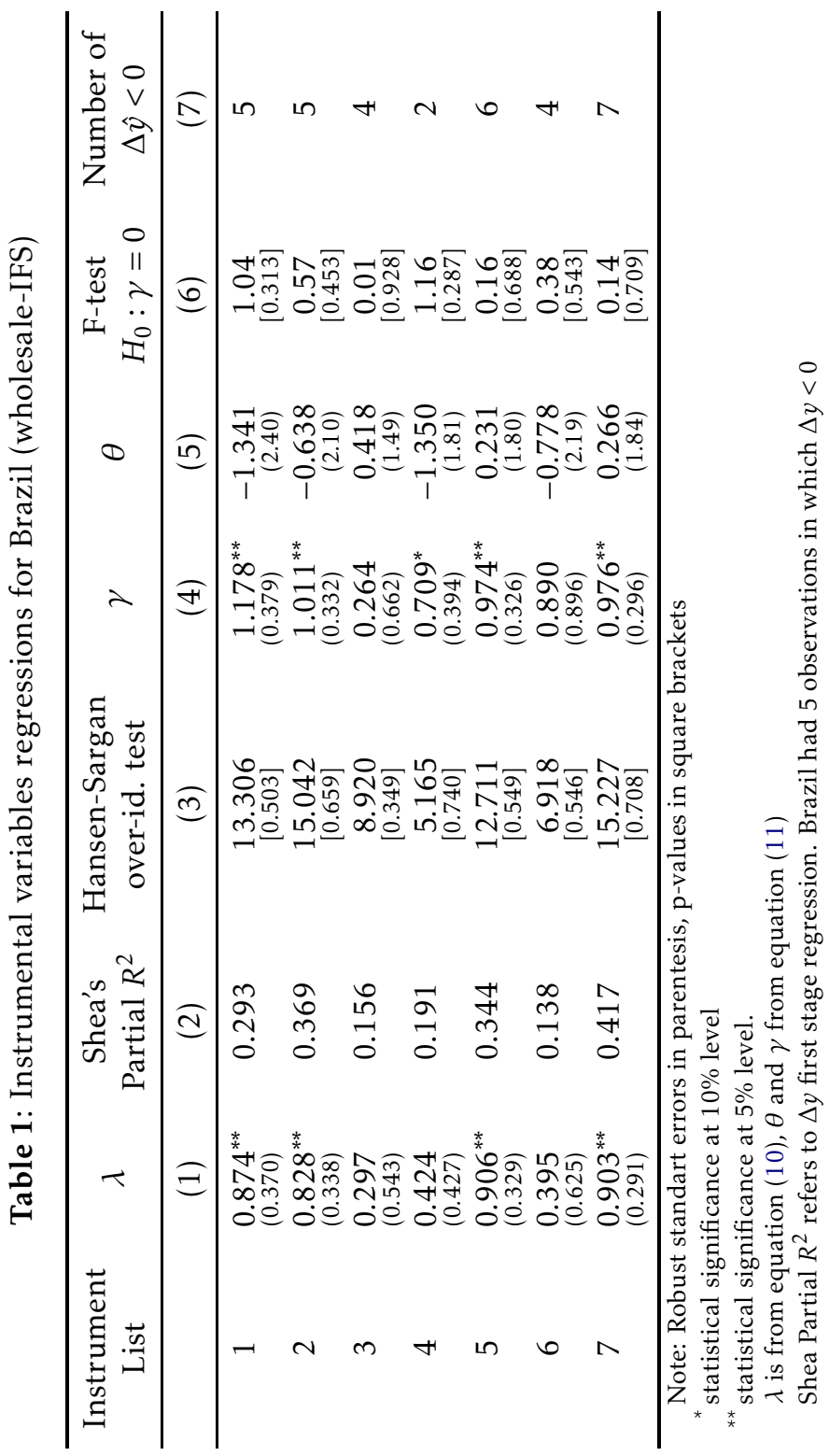




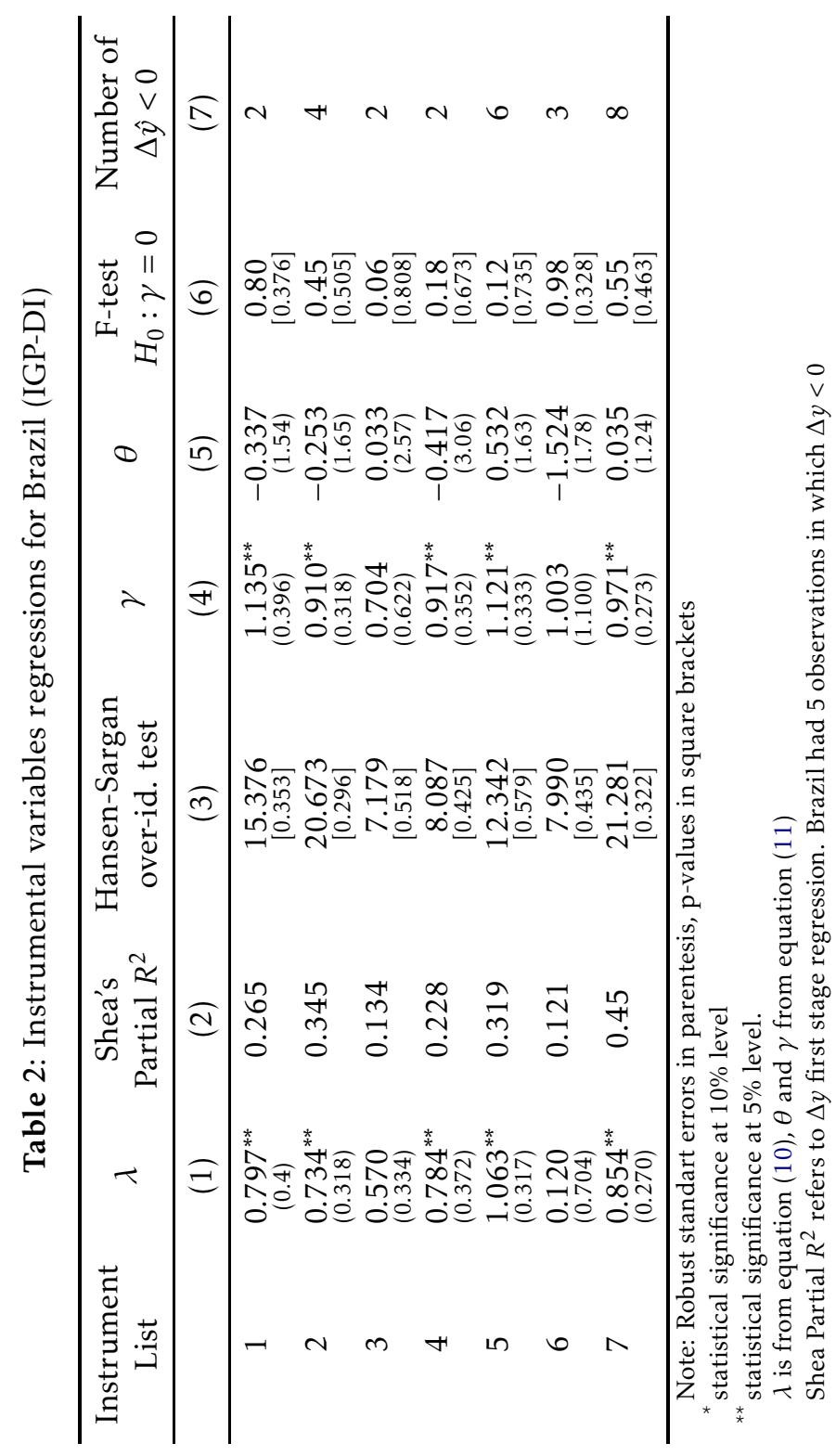


0.61 , and Gomes (2004) obtained a $\lambda$ of 0.85 . The only different estimate came from Cavalcanti (1993) with an estimated $\lambda$ of about 0.32 .

Table 3 display the results for Colombia, which are very surprising because for all instrument lists the estimated $\lambda$ s are statistically significant at $5 \%$ level and are all larger than one, ranging from 1.245 to 1.502 . This result is not contemplated in CM's framework and can be an indicative that equation (10) has a specification problem, although there are no rejections in the over-identification tests. A possible explanation could be instruments with low predictive power, however, we did not find support for it because there are some specifications such as 2, 5, and 7 that have large Shea's Partial $R^{2}$ (reported in column 2).

The results for Peru are reported in table 4. For all seven instrument lists the estimated $\lambda \mathrm{s}$ are statistically significant at $5 \%$ level. The point estimates range from 0.822 to 1.111 , and are concentrated around one. There are no rejections in the over-identification tests. These last two findings are also present in the Colombian estimates.

Table 5 exhibits the results for Venezuela. We can see that $\lambda$ is not statistically significant at 5\% level only with instrument lists 3 and 4 , that also presented the lowest Shea's Partial $R^{2}$, which are almost zero. The statistically significant results provide a point estimates between 0.703 and 1.043, and 1.043 is the only estimate above one. There are no rejections in the overidentification tests for Venezuela.

A common fact across all countries (and tables) is that the estimates from instrument lists (1) and (2) are very similar. In addition to no rejections in the over-identification tests, it seems that there is no difference in using instruments from the second lag and from the third lag. Thus, there is indirect evidence of the absence of an MA(2) in the error term. Perhaps we are not finding this MA(2) error term due to the use of annual data, but this stills an open question to be further pursued in another paper.

The cross-country evidence produced so far can be contrasted with the findings of Gomes \& Paz (2004), who used the CM's framework and a similar dataset for 1950 to 2000. They also find evidence of rejection of the LCH-PIH for Brazil, Colombia and Peru, in particular their estimates of $\lambda$ for Colombia and Peru are smaller ( 0.62 and 0.48 respectively) than ours.

Despite these point estimations differences, the evidence against the $\mathrm{LCH}$ $\mathrm{PIH}$ is clear, hence it is imperative to investigate the reasons behind such failures. Thus, we estimate the equation (11) in an attempt to clarify if myopia and liquidity constraints could be behind this rejection.

Table 1 reports estimates for Brazil when the wholesale price index is used to calculate the inflation rate. Column (4) reports the estimated $\gamma$ that are positive, but statistically significant, at $5 \%$ level only for instrument lists 1 , 2,5 , and 7 , which have the largest Shea's Partial $R^{2}$ measures. The estimated $\theta$ is presented in column (5), and none of them are statistically significant. These results suggest a liquidity constraint motive for failure of LCH-PIH. Nevertheless, the $F$-test for $\gamma=\theta$ was not able to reject this null hypothesis for all instrument lists, at $5 \%$ level, and this fact weakens the evidence in favor of liquidity constraint. A key issue here is the large standard error of $\theta$. This lack of precision may be due to the small number of periods with negative income, five periods or approximately $10 \%$ of the years. From column (7) we can see that the instruments seem to be able to predict the decline in income in similar numbers to the actual declines. When the Brazilian inflation was 


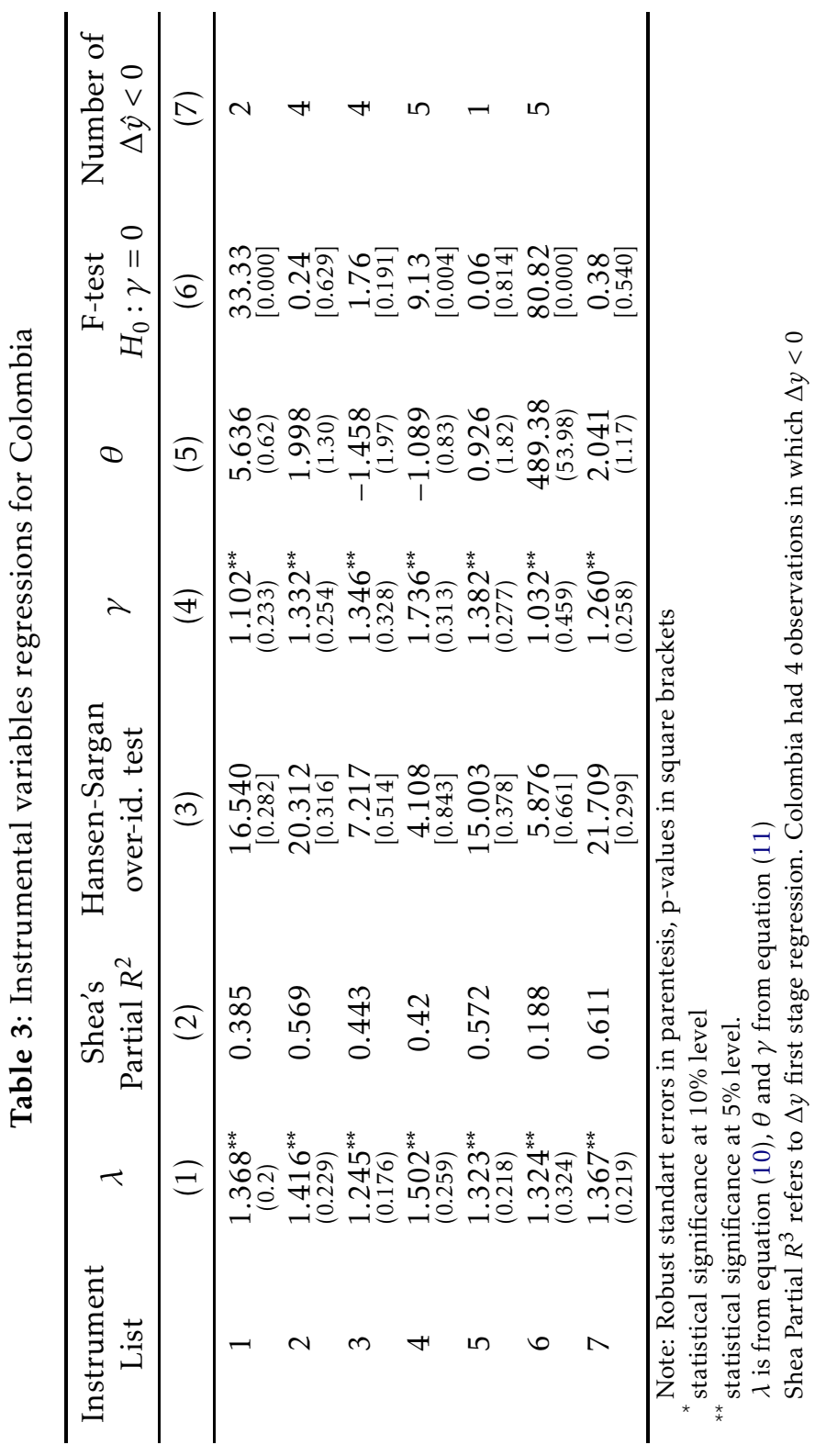




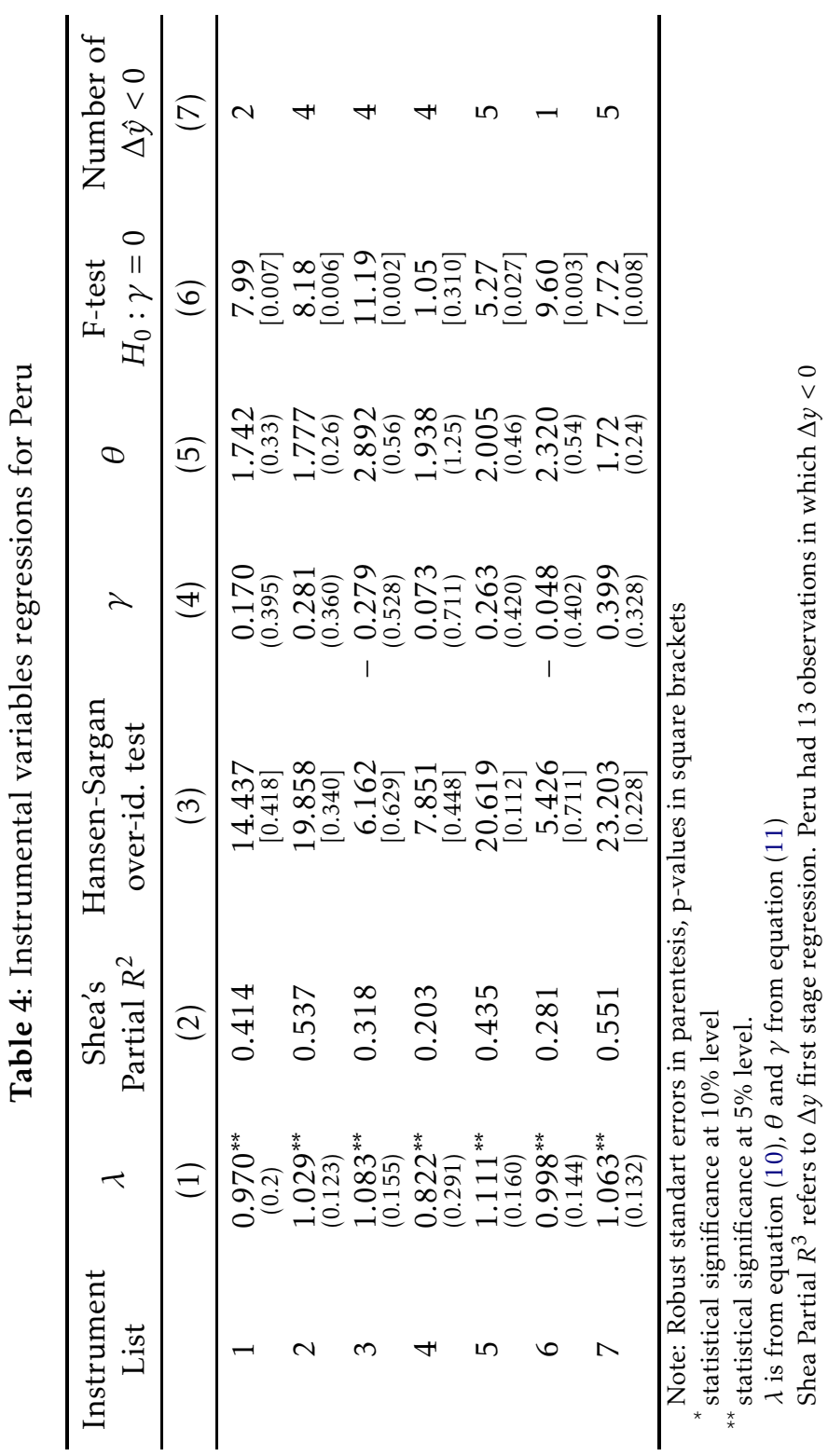




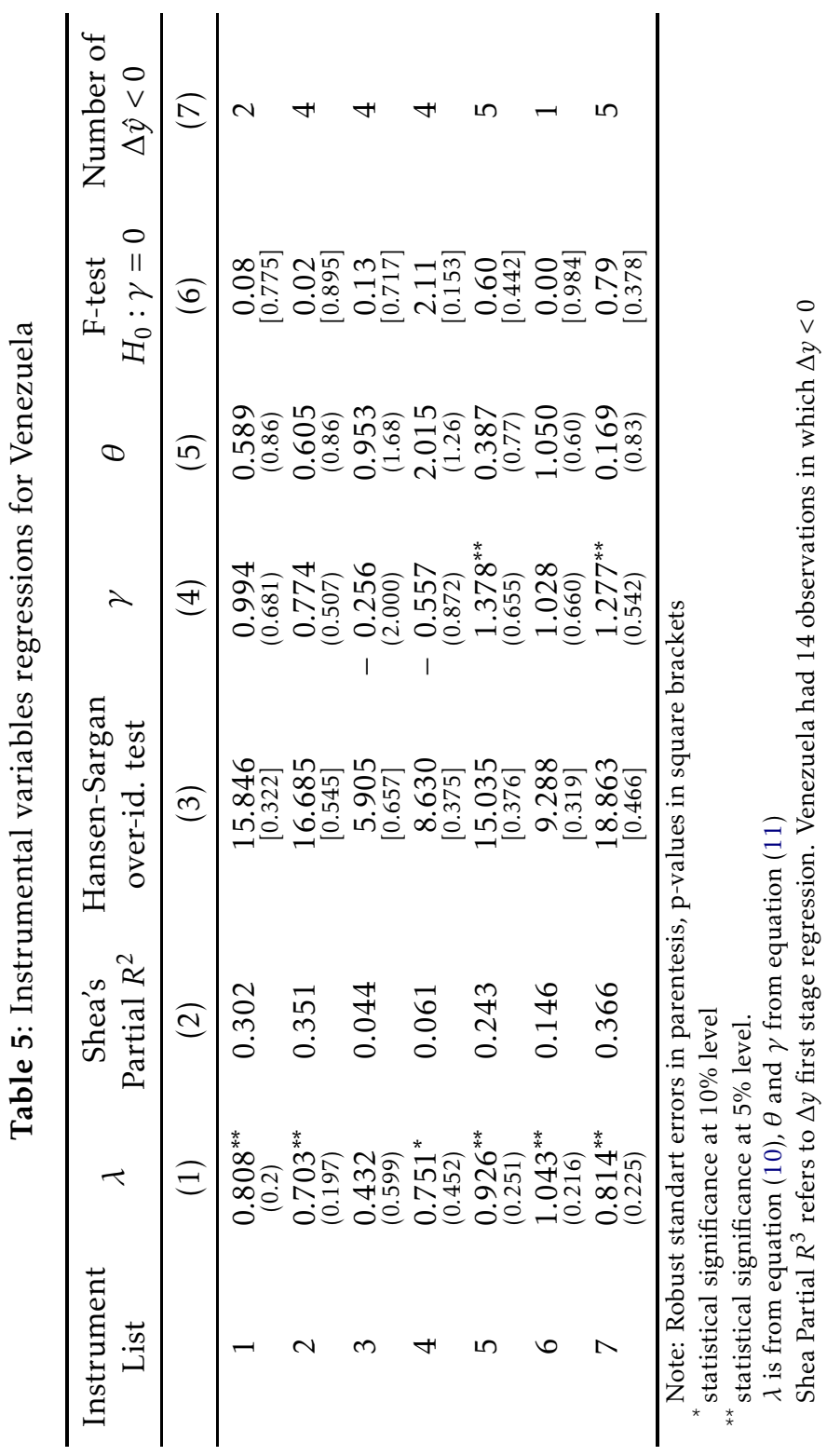


calculated using the IGP-DI price index, the results in table 2 are similar to the ones discussed above.

The results for Brazil are in line with Gomes (2010), which used an annual sample. However, these results are different from the ones obtained by Paz (2006), which find evidence of perverse asymmetry. A possible reason for that is that his sample is quarterly data and started in 1991, while our paper has annual data and started in the 1950. Furthermore, throughout this period the Brazilian economy underwent significant structural changes, in particular in the banking sector that could have changed credit availability to consumers. Yet the reason behind these contradictory results is still an open question.

Results for Colombia are depicted in table 3. The estimated $\gamma \mathrm{s}$ are all positive and statistically significant at the 5\% level. In column (5), the estimated $\theta$ s show a different picture. Only the instrument lists 1 and 6 present statistically significant estimates, at $5 \%$ level, with very large coefficients. Coincidently, these are the instrument lists with the lowest Shea's Partial $R^{2}$, which suggest that we consider these two results cautiously. As happened with Brazilian data, the standard deviations of the estimated $\theta$ s are also large. We also suspect that this lack of precision comes from the small number of periods with actual income declines. The $F$-test null hypothesis $\gamma=\theta$ is rejected at $5 \%$ level of confidence only for specifications 1 and 4 . In spite of specifications 1 and 6 results, we believe Colombian data lends some support to the liquidity constraint motive.

The estimates output for Peru are shown in table 4. We can see from column (4) that the estimated $\gamma$ s are never statistically significant, whereas the estimated $\theta$ s in column (5) are positive and statistically significant except in specification 4 , which is also the one with the lowest Shea's Partial $R^{2}$. So far, the results clearly do not support the liquidity constraint hypothesis. Column (6) brings the $F$-test for null hypothesis $\gamma=\theta$ which is not rejected only for specification 4 . Thus, there is no evidence in favor of myopic consumers, but we can see that Peruvian consumers are more sensitive to decrease in income growths, which is a similar pattern to what Shea $(1995 a, b)$ found for U.S. economy: the perverse asymmetry. It is important to mention that in comparison with Brazil and Colombia, Peru presented considerably more periods in which income declined and the precision of the estimated $\theta$ s are considerably better.

Table 5 exhibits the results for Venezuela. Only instrument lists 5 and 7 present statically significant estimated $\gamma$ coefficients. In none of the specifications the estimated $\theta$ is statistically significant. Moreover, the null hypothesis $\gamma=\theta$ is not rejected for all instrument lists. After all, it is not clear who is the culprit behind the failure of LCH-PIH in Venezuela. Instrument lists 5 and 7 estimates suggest liquidity constraint, but at the same time the $F$-tests indicate that this is not the case. Like Peru, Venezuela experienced decline in income in several years, so the ambiguous result found cannot be blamed on this.

\section{Conclusions}

We investigated if the Life Cycle-Permanent income hypothesis is able to explain the consumption growth rate for the following South American countries: Brazil, Colombia, Peru, and Venezuela. When the approach of Camp- 
bell \& Mankiw (1989) was used, the LCH-PIH was rejected for all countries. To investigate the reasons behind the rejection of the LCH-PIH, we employ Shea $(1995 a)$ model which encompass three hypotheses: myopia, liquidity constraints and perverse asymmetry.

Our findings support that for Brazil there is signs of liquidity constraints, although we are not able to reject statistically the hypothesis $\gamma=\theta$, which seems to be a consequence of a imprecise estimate of $\theta$. For Colombia we also find evidence in favor of liquidity constraints, especially if we focus on instrument lists with better. The results for Peru show signs of perverse asymmetry, as documented for U.S. by Shea $(1995 b, a)$. And, the results for Venezuela are uninformative, in the sense that we could not identify the reason behind the rejection of LCH-PIH. Some of our results were in line with the literature that used similar data and period. Interestingly, our results differed from Paz (2006) results for Brazil, and one reason could be the different coverage of his sample, but such difference in results is still an open question.

Last, but not least, it is worth mentioning that CM and Shea (1995a) frameworks are based on strong auxiliary assumptions, such as log-normality. To be precise, the behavior under the LCH-PIH is obtained using an approximation of the Euler Equation, so the data for Brazil, Colombia, Peru and Venezuela rejected the LCH-PIH when such approximations are used.

\section{Bibliography}

Altonji, J. \& Siow, A. (1987), 'Testing the response of consumption to income changes with (noisy) panel data.', Quartely Journal of Economics 102, 293328.

Angeletos, G. M., Laibson, D., Repetto, A., Tobacman, J. \& Weinberg, S. (2001), 'The hyperbolic consumption model: calibration, simulation, and empirical evaluation.', Journal of Economic Perspectives 15, 47-68.

Brady, R. R. (2008), 'Structural breaks and consumer credit: Is consumption smoothing finally a reality?', Journal of Macroeconomics 30, 1246-1268.

Caballero, R. (1994), 'Notes on the theory and evidence on aggregate purchases of durable goods', Oxford Review of Economic Policy 10, 107-117.

Campbell, J. \& Mankiw, N. (1989), Consumption, income and interest rates: reinterpreting the time-series evidence, MIT Press.

Campbell, J. \& Mankiw, N. (1990), 'Permanent income, current income, and consumption', Journal of Business and Economics Statistics 8, 265-279.

Carrol, C. D. (1997), 'Buffer-stock saving and the life cycle/permanent income hypothesis', Quartely Journal of Economics 112, 1-55.

Cavalcanti, C. (1993), 'Inter-temporal substitution in consumption: an empirical investigation for brazil', Brazilian Review of Econometrics 13, 203-229.

Engelhardt, G. V. (1996), 'Consumption, down payments and liquidity constraints', Journal of Money, Credit and Banking 28, 255-271.

Flavin, M. (1981), 'The adjustment of consumption to changing expectations about future income.', Journal of Political Economy 89, 974-1009. 
Flavin, M. (1985), 'Excess sensitivity of consumption to current income: Liquidity constraints or myopia?', Canadian Journal of Economics 18, 177-136.

Garcia, R., Lusardi, A. \& Serena, N. (1997), 'Excess sensitivity and asymmetries in consumption: An empirical investigation', Journal of Money, Credit and Banking 29, 157-176.

Gomes, F. (2004), 'Consumo no brasil: Teoria da renda permanente, formação de hábito e restrição à liquidez', Revista Brasileira de Economia 58, 381-402.

Gomes, F. A. R. (2010), 'Consumo no brasil: Comportamento otimizador, restrição de crédito ou miopia?', Revista Brasileira de Economia 64(3), 261275.

URL: http://econpapers.repec.org/RePEc:fgv:epgrbe:v:64:n:3:a:3

Gomes, F., Issler, J. \& Salvato, M. (2005), 'Principais características do consumo de duráveis no brasil e testes de separabilidade entre duráveis e nãoduráveis', Revista Brasileira de Economia 59, 33-60.

Gomes, F. \& Paz, L. (2004), 'Especificações para a função consumo: testes para países da América do Sul', Pesquisa e Planejamento Econômico 34(1), 3955.

Gourinchas, P. \& Parker, J. (2001), 'The empirical importance of precautionary saving', American Economic Review 91, 406-412.

Hall, R. (1978), 'Stochastic implications of the life cycle-permanent income hypothesis: theory and evidence', Journal of Political Economy 91, 249-265.

Hansen, L. P. \& Singleton, K. J. (1983), 'Stochastic consumption, risk aversion, and the temporal behavior of asset returns', Journal of Political Economy 91, 249-265.

Heston, A., Summers, R. \& Aten, B. (2002), Penn world table version 6.1, Technical report, Center for International Comparisons at the University of Pennsylvania.

Heston, A., Summers, R. \& Aten, B. (2006), Penn world table version 6.2, Technical report, Center for International Comparisons of Production, Income and Prices at the University of Pennsylvania, http://pwt.econ.upenn.edu/.

IFS (2008), International financial statistics, Technical report, IMF, Washington.

Issler, J. \& Rocha, F. (2000), 'Consumo, restrição a liquidez e bem-estar no brasil', Economia Aplicada 4, 637-665.

Jappelli, T. \& Pagano, M. (1989), 'Consumption and capital market imperfections: An international comparison.', American Economic Review 79, 1088 1105.

Kahneman, D. \& Tversky, A. (1984), 'Choices, values and frames', American Psychologist 39, 341-350. 
Madsen, J. \& McAleer, M. (2000), 'Direct tests of the permanent income hypothesis under uncertainty, inflationary expectations and liquidity constraints', Journal of Macroeconomics 22, 229-252.

Mankiw, N. (1981), 'The permanent income hypothesis and the real interest rate', Economics Letters 7, 307-311.

Mankiw, N. G. (1982), 'Hall' consumption hypotesis and durable goods', Journal of Monetary Economics 10, 417-425.

Nelson, C. \& Startz, E. (1990), 'The distribution of the instrumental variables estimator and its t-ratio when the instrument is a poor one', Journal of Business 63, 125-140.

Paz, L. (2006), 'Consumption in brazil: myopia or liquidity constraints? a simple test using quarterly data', Applied Economic Letters 12, 961-964.

Reis, R., Issler, J., Blanco, F. \& Carvalho, L. (1998), 'Renda permanente e poupança precaucional: Evidências empíricas para o brasil no passado recente', Pesquisa e Planejamento Econômico 28, 233-272.

Sarantis, N. \& Stewart, C. (2003), 'Liquidity constraints, precautionary saving and aggregate consumption: an international comparison', Economic Modelling 20, 1151-1173.

Sarno, L. \& Taylor, M. (1998), 'Real interest rates, liquidity constraints and financial deregulation: Private consumption behavior in the u.k.', Journal of Macroeconomics 20, 221-242.

Shea, J. (1995a), 'Myopia, liquidity constraints, and aggregate consumption: A simple test', Journal of Money, Credit and Banking 27, 798-805.

Shea, J. (1995b), 'Union contracts and the life cycle-permanent income hypothesis', American Economic Review 85, 186-200.

Shea, J. (1997), 'Instrument relevance in multivariate linear models: A simple measure', The Review of Economics and Statistics 79, 348-352.

Vaidyanathan, G. (1993), 'Consumption, liquidity constraints and economic development', Journal of Macroeconomics 15, 591-610.

Yogo, M. (2004), 'Estimating the elasticity of intertemporal substitution when instruments are weak', The Review of Economics and Statistics 86, 797810 .

Zeldes, S. P. (1989), 'Consumption and liquidity constraints: An empiri- cal investigation', Journal of Political Economy 97, 305-346. 